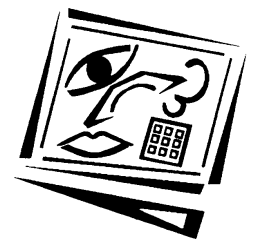

\title{
Design, sharing and co-construction of learning resources: A case of lifelong learning communities in Shanghai
}

\author{
Xiaoqing $\mathrm{Gu}$ \\ East China Normal University \\ Chongping Zha \\ Qujing Normal University \\ Shusu Li \\ East China Normal University \\ James M. Laffey \\ University of Missouri-Columbia
}

\begin{abstract}
A key problem in developing a virtual community for co-constructing learning resources is the need to have people volunteer to share their expertise. In this paper, we introduce the first phase of our research in which we examine strategies for encouraging participants to share in the system. We began by designing an intervention model based on creating and sustaining social capital among the participants for the entire resource development process. Data collected in this pilot for the first phase showed that this design was effective in attracting and maintaining users' interest in contributing to this virtual community, while leaving some designed functions and tools still in need of improvement. These findings will be used to make modifications for a future version of the system, and their implications to the social computing field are addressed also.
\end{abstract}

\section{Introduction}

Sharing is an important aspect of being a member of a virtual community (Wasko \& Faraj, 2005) and of having a vital role in it. Unfortunately, even in an age that has well established trends toward user-led content as Bruns (2007) claimed, sharing activities that require effort and skill are comparatively less frequent than in a more structured online environment where only inputs such as filling in forms or adding comments are needed (Kalmus, Pruulmann-Vengerfeldt, Runnel \& Siibak, 2009). Understanding what drives individuals and how to stimulate their willingness to invest in sharing is crucial in our co-construction system (Co-Cons), where the needed sharing activity is to create and share mobile learning resources from people with different backgrounds and expertise.

The Co-Cons system has been designed as a mechanism for developing mobile learning resources which then will be available for download onto mobile devices by lifelong learners. The Co-Cons system works within a lifelong learning network being developed by the Shanghai government to build an open, accessible learning network for all Shanghai citizens. Co-Cons will enable all users of the lifelong learning network, who typically have different backgrounds and preferences, to collaborate with each 
other in creating mobile learning resources which could be downloaded to mobile devices for casual reference $(\mathrm{Gu} \& \mathrm{Li}, 2010)$. The system is designed as an instance of social computing tools. Similar to better known social computing initiatives of blogging, Wikipedia, Flickr, etc, Co-Cons can be characterised as shifting the locus of control for creation and configuration of content to the grassroots (Parameswaran \& Whinston, 2007; Wang, 2007). Yet different from those popular social computing systems, the objective for sharing behaviour in this system is the creation of mobile learning resources. The Co-Cons system envisions these learning resources being completed collectively by users with similar interests in a Co-Cons task area, by editing scripts, uploading materials, tagging on objects and participating in a variety of activities, such as reviewing the work of others, that contribute their intelligence to constructing high quality learning resources.

Co-Cons can be considered to be a special case of the broader set of online content creation activities carried out in those popular social computing systems, such as editing profiles, blogging, participating in forums and so forth (Acar, 2008; Kalmus et al., 2009; Bruns, 2007). To ensure that the resources co-constructed in the system by different users meet a basic quality standard, there is a procedure designed within the system, with various templates and tools provided which scaffold and guide the users to design and develop the resource in an effective way. In the system, a Co-Cons task will be initiated when the practical learning needs expressed by users reach a threshold number. Once the Co-Cons task is established, users interested in the same topic participate in the co-construction of a learning resource. During the Co-Cons task, users edit the resource scripts, contribute resource material, and make tags or comments shared by others by sharing their expertise in the task area. In this process users, who do not necessarily know each other from across the lifelong learning network, are supported in a co-construction process with each other. Designing an effective sharing mechanism is critical to the eventual success of the Co-Cons system.

The goals of this research are to design the sharing mechanism within the Co-Cons system to stimulate users to participate and share in the virtual community and to build new knowledge about sharing and co-construction by online communities. To do so, we explore the factors involved in attracting participation and willingness to share and, how these factors are jointly engaged to bring about sharing in the Co-Cons community. A hypothetical intervention model has been designed to guide the development of mechanisms to stimulate and ensure the effective operation of the learning resource co-construction system. Moreover, this study can be helpful to answer the problems most communities are faced with, such as how to foster a selfsustaining sharing culture with intentional interventions.

\section{Theoretical background and research model}

\section{Factors involved}

Contrasted with a geographical community of practice, which has strong interpersonal ties and created norms (Lave \& Wenger, 1991; Wenger, 1998), virtual communities may consist of a larger, loosely connected, geographically distributed group of individuals (Brown \& Duguid, 2001). Therefore in order to be successful, deliberate planning is needed to account for the factors involved in the process of community development, as Preece (2000) suggested. 
It is possible to generate an extensive list of factors related to sharing in a virtual community by examining the literature on virtual communities. These include trust, social network ties, beliefs and attitudes, experience of sharing, expectations of benefits, and even usability of a virtual community (Andrews et al., 2002; Chiu et al., 2006; Hsu et al., 2007; Ardichvili, 2008; Lin et al., 2009; Wasko \& Faraj, 2005; Chen et al., 2009; Bock et al., 2005; Raban \& Rafaeli, 2007; Preece, 2000). How do these factors work with each other to have a positive effect on the community? By comparing the development of a virtual community with the actions of a new city mayor, Preece (2000: 26) claimed that basic policies should be put in place to provide a framework of social growth and evolution. In this metaphor, factors involved in a community should be managed to discourage inappropriate behavior and facilitate desired ones, so as to make the virtual community thrive.

\section{Social capital model}

Sociologists studying face to face communities have identified 'social capital' as a key feature of a virtual community (Coleman, 1990; Nahapiet \& Ghoshal, 1998). This research was later extended by using social capital as an important construct in interpreting the ties that bind strangers together so as to participate and sustain interest in online communities (Ganley \& Lampe, 2009; Jiang \& Carroll, 2009). Nahapiet and Ghoshal (1998: 243) defined social capital as "the sum of the actual and potential resources embedded within, available through, and derived from the network of relationships possessed by an individual or social unit". Considering the direct relationship between social capital and development of a successful virtual community, we strived to direct our inquiry into how to develop sharing and coconstruction in a virtual community from the lens of social capital theory. By carefully designing sharing mechanism, we hoped to harness the value of social capital and to foster reciprocity, coordination, communication and collaboration.

The factors listed above were clustered into three facets in a social capital model: the structural, the relational, and the cognitive dimensions (Nahapiet \& Ghoshal, 1998). According to Nahapiet and Ghoshal (1998: 244, 251), the structural dimension of social capital refers to the overall pattern of relationships among social actors. Network ties and network configuration are main constructs of this dimension. The relational dimension describes the kind of personal relationships people have developed that act as social bonds to influence social behavior and fulfill social motives. The main aspects of this dimension include trust, norms, obligations and identification. The cognitive dimension refers to shared resources in a community which include shared meaning, representation and interpretation, and could be exemplified by their attributes, namely shared vision or shared values that facilitate action towards collective goals or tasks in the community (Chiu et al. 2006; Yang \& Farn 2009).

Social capital and its factors in these three dimensions exhibit a kind of "chicken and egg' dilemma in which Andrews et al. (2002) discussed the relationship of 'good sociability' and how to build it in a virtual community. From the perspective of community building, it is not enough to explain the factors with the social capital model, rather the design of comprehensive interventions for cultivating, attaining, or increasing social capital, so as to facilitate sharing behavior, are crucial. Enabling social capital facilitates participant's actions, and can be accumulated, attained and increased through various strategies (Ginsburg \& Weisband, 2002; Daniel et al., 2002). For example, Smith (2008) proposed that since individuals were complex entities whose 
attitudes and behaviors were prone to change over time, social capital needs to be developed along with these changes, from potential social capital to actual social capital.

Although relatively little research has been focused on developing intervention models which foster social capital, some lessons can be drawn from related research on strategies, policies and actions, such as action models for virtual communities (Andrews et al., 2002; Andrews, 2002; Preece, 2000), community formation patterns (Goggins et al., 2007) and impacts of contextual factors (Lin et al., 2009). Additionally, our own previous work on an intervention model can also provide guidance (Gu \& Zha, 2008). Andrews argued that special effort should be taken to facilitate willingness of participation in virtual communities. These efforts embodied in his action model were designed as strategies to draw people into an online community, by building their trust and interest stage by stage (Andrews et al., 2002; Andrews, 2002). Similarly, Goggins et al. (2007) described how users form small groups within an online learning setting, and explained how tools and cooperative tasks influence formation of virtual community. Lin et al. (2009) claimed that contextual factors drive sharing and could be managed by introducing sharing initiatives and creating shared culture. Preece (2000:27) proposed that plans for a successful virtual community should include both sociability and usability. In our own previous work, we also proposed an intervention model in which strategies, actions and tools work together to facilitate participation and the collaboration process (Gu \& Zha, 2008).

To guide the current research, we identified factors for facilitating willingness to share in a Co-Cons system from the social capital model of structure, relational and cognitive dimensions, and then designed an intervention model with the intention of developing and increasing these three dimensions of social capital by strategies, functions and tools, so as to attract participation, and foster sharing motivation, willingness, behaviour and capacity.

\section{Mechanism design}

The intervention model we developed as a sharing mechanism within the Co-Cons system is shown in Figure 1. With designed strategies, functions and tools, this intervention model is expected to foster and increase social capital and therefore foster willingness and participation in the co-construction process.

\section{Intervention strategies}

The strategies listed in the second column of Figure 1 aim at building ties and organisation, through Attracting participation and Maintaining organisation, and fostering the identity, trust and norms needed to take part in collaborative tasks by Orienting roles, Making results perceptible and Accumulating credit. Other strategies address cognitive objectives, such as making the individual comfortable and confident in collaborative activities, by Ensuring usability and Keeping track, and creating shared resources through a shared endeavour, such as in Accepting mutual outcomes.

The Structural dimension of forming social capital refers to the overall pattern of connections between participants in a virtual community (Nahapiet \& Ghoshal, 1998). Network ties and Organisation are main constructs in this intervention model, indicating who you reach and how you reach them. Clearly stated goals will attract people with similar interests to help in creating stable communities (Preece, 2000). In developing a 
new social computing system, strategies of participation attracting and organisational maintenance are designed to create purposeful network ties for people having mutual interests, and further create maintainable linkages based on mutual interests.

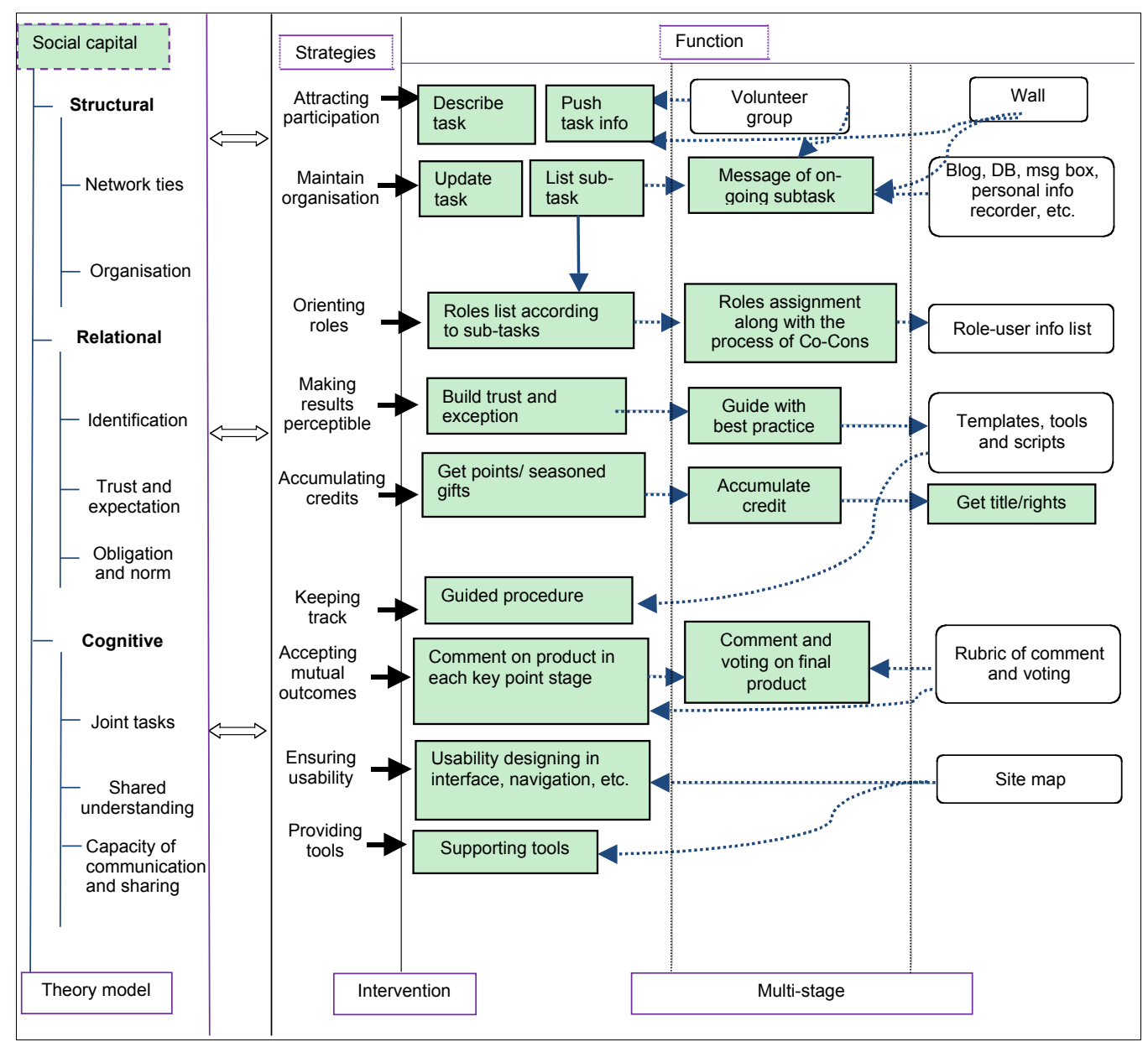

Figure 1: Intervention model for increasing social capital

The Relational dimension of social capital is a kind of "actor bonds" that people develop with each other through a history of interactions (Nahapiet \& Ghoshal, 1998). According to Preece (2000), carefully crafted policies play a major role in cultivating these bonds by guiding behaviour, supporting cooperation and deterring antisocial behaviours. In order to catalyse the development of Identification, Trust and expectation, as well as Obligation and norms, intervention strategies should include actor orientation, making the result perceivable to the participants, and showing accumulating credits so as to help users build their identity, trust, and obligation to engage in the virtual community for mutual benefit.

The Cognitive dimension of social capital refers to the shared representations and interpretations of system meaning (Nahapiet \& Ghoshal, 1998), and is interpreted in Wenger (1998) as a kind of shared repertoire, which makes communities function well 
with a combination of mutual engagement and joint enterprise. In the Co-Cons system where users mutually depend on each other to construct resources, the joint tasks and shared understanding about the tasks under construction are typical assets of this dimension. Furthermore, in an online environment where interaction is highly dependent on available tools, capacity for communication and sharing is added as the third construct in this model, where usability is critical in the online tools available for making an environment for sharing. Thus, strategies are respectively designed to keep track of mutually interesting tasks, to elect mutually acceptable versions by comments and votes, and to make participants feel comfortable with usability design and appropriate tools.

\section{Intervention functions}

The Strategies of column 2 are achieved through the corresponding Functions shown in the third column of Figure 1. These functions are designed to be carried out when the system starts to work and during its operation. Since the functions are purposely designed, they are supported by tools (represented as ovals in figure 1) within the system. In addition, multi-stage functions are designed with the intention of building social capital stage by stage (Andrews et al., 2002; Andrews, 2002).

\section{Attracting participation}

In a task-oriented collaboration setting like our Co-Cons system, finding mutually interesting tasks is the most important factor to attract and connect users into a community (Nahapiet \& Ghoshal, 1998). Research shows that self interest influences willingness of users to participate and determines the extent of sharing (Raban \& Rafaeli, 2007; Andrews et al., 2002). Meanwhile, clearly stated goals appear to attract people with similar goals according to Preece (2000). Functions in the intervention model include clearly describing the co-construction tasks and pushing information about co-construction tasks to attract potential participants who will be interested in the tasks to be completed. In our study the tasks' description will be described by the users in the "leader group". In our usage model new tasks will be triggered when the needs requested from the large body of users reach a threshold number in the system. Requests are posted by users on the Wall which is designed to be an attractive and social way for users to share their thoughts and wishes. Figure 2 shows a screen picture of the Wall.

\section{Maintaining organisation}

Functions aimed at maintaining an organisation based on mutual interests and collective tasks are designed to keep the task and its sub-tasks clearly stated and updated, making what will happen next to be strongly focused. To maintain a community based on mutually interesting ties, tools such as message boxes, discussion boards and blogs are provided as suggested in previous research (Chiu et al., 2006; Ardichvili, 2008). Clearly stated messages about the on-going sub-task and its construction activities are circulated in a message box, while questions and answers are discussed on the task-based forums. Users in the leader group act as mediators in this process (Preece, 2000).

\section{Orienting roles}

Identity in social terms is viewing the participant as part of a community of practice (Wenger, 1998), a community where participants sense strong identification with one another and experience meaningful connections based on trust and mutual intentions, all of which work harmoniously together to reach greater levels of sharing (Chiu et al., 
2006; Tsai, 2002). Research also suggests that maintaining a core of experienced individuals is an important approach (Tsai, 2002). In the Co-Cons system, core users are identified as the leader group users who will be upgraded from being ordinary users as their credit accumulates. Different groups of users have different roles and tasks, which will be listed with detailed instructions within the co-construction task period for users to follow, where sub-tasks can only be selected in a proper order according to the stages of the construction process (Role assignment), to avoid potential conflict between different users.

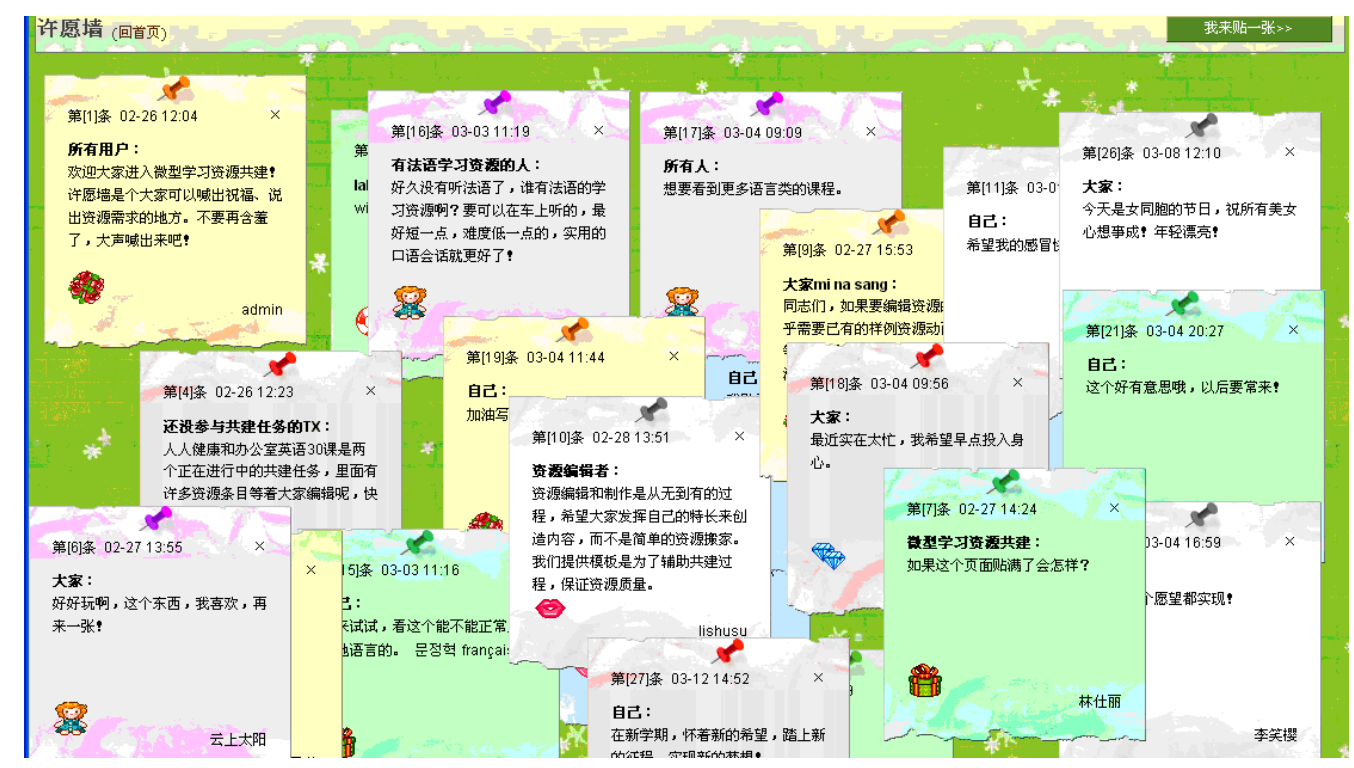

Figure 2: Screen picture of the Wall

\section{Making results perceptible}

Research shows that trust, self-efficacy and outcome expectation are critical determinants of sharing (Andrews et al., 2002; Chiu et al., 2006; Hsu et al., 2007; Ardichvili, 2008; Lin et al., 2009). Thus, examples of best practice of finished products and tutorials are provided in this system to help users understand what they are expected to finish; templates, tools and scripts are provided in the different stages to help users know how to complete the actions which their roles require, all of which are designed to make the collaborative tasks achievable. As well, the intention is to make outcome expectations concrete to users with perceptible advantages and benefits as suggested by Lin et al. (2009) and Ardichvili (2008), and to increase their self efficacy so that they will believe they will be able to share in the community successfully as suggested by Hsu et al. (2007).

\section{Accumulating credit}

Reputation, respect and various kinds of rewards are factors which influence willingness to share (Hsu et al., 2007; Chiu et al., 2006; Ardichvili, 2008; Lin et al., 2009; Bock et al., 2005); these are simultaneously formed with responsibility regulated by norms and obligations (Hendriks, 1999). The norm in our system is that fulfilling one's obligations makes for a good reputation. Users will gain points for their contributions accordingly, such as editing scripts, contributing material, commenting and voting, and other sharing behaviours. Consequently, a list of the top ten active contributors 
will be shown and be updated on the front page of the system according to the points they have collected. Meanwhile, users will accumulate their credits, and receive their titles within the system. Furthermore, users will get gifts as another kind of reward.

\section{Keeping track}

Mutually interesting tasks attract users into a co-construction task, and the various tools of communication which are provided in the system help to maintain the sense of community. However, from the cognitive dimension of social capital, shared endeavours and collective engagement in the collaboration produce more commitment for the co-construction. Therefore, a guided procedure is designed within the system, with templates and tools provided in the respective stages, to help users to keep track of joint tasks, and "make it easier to contribute" (Nielsen, 2006).

\section{Accepting mutual outcomes}

Mutual engagement in a joint task creates a shared repertoire in the community (Wenger, 1998). Toward the strategy of shared understanding, the mutually accepted versions of co-constructed products in each key-point stage will be commented upon by users, the mutually accepted final version of the co-constructed product will also be commented upon and voted on by users, and finally, finished co-constructed products will be ranked by users by referring to related rubrics available in the system. Accordingly, a list of 'recommended resources' will be presented on the front page according to the votes and comments they have gained.

\section{Ensuring usability}

Research shows that the experience of sharing, technological aptitude or acceptance, and feeling comfortable are all important factors influencing sharing (Ardichvili, 2008; Andrews et al., 2002; Wasko \& Faraj, 2005). In our intervention model this construct is defined as the users' capability for communication and sharing, and also the capacity that the environment afforded, such as the tools or scaffolds available for users, and the usability of the community environment. After all, having users be comfortable in the virtual community is an important factor influencing their sharing behaviours (Preece, 2000). In our system, then, efforts were made in promoting usability in layout, interface, and navigation, as well as providing a site map, all making users feel comfortable in this online collaborative setting.

\section{Providing tools}

Supportive tools is one of the three enablers that Ardichvili proposed (2008). As a strategy to build capacity for communication and sharing, tools are provided in the system, as mentioned in different stages of the co-construction process, to attract participation (such as Wall), to maintain the community (such as Message Box), to help carry out a particular sub-task (such as templates), and to build mutually acceptable shared resources (such as rubrics).

Furthermore, a leader group of users will be constituted to act as moderators and mediators in the co-construction process playing a key role in the virtual community (Preece, 2000). The members of the leader group coordinate all of the sharing activities with the use of message boxes and discussion boards, making the co-construction process continual by making final decisions while thoughtfully reviewing the comments and votes of the users at each interval. This role of the leader group is also a part of the designed intervention model. 
For the sake of clarity, we described the intervention of each dimension independently of the other dimensions. We recognise, however, that these constructs, interventions and their respective measures are likely to be interrelated in complex ways. For example, both trust and self-efficacy could result as a benefit from the strategy of Ensuring usability.

\section{Methodology}

A design-based research (DBR) approach has been used in developing the Co-Cons system with the sharing mechanism as its key component. Following the method of DBR (Amiel \& Reeves, 2008), iterative improvement of the sharing mechanism as well as the system itself along with advancing theory about online sharing and coconstruction are the goals of the research process. In this current study, we intend to build knowledge about how this first iteration of the sharing mechanism works as a facilitator of sharing from the data collected in this first round pilot study. The intervention model is used as a framework for data collection and analysis. Findings in this pilot will be used to make successive improvements to the mechanism design and overall system, as well as seek insights about human to human interaction via the computer.

\section{Pilot procedure}

A group of 17 graduate and undergraduate students from a university in Shanghai participated voluntarily in the three-week pilot from February to March 2010. An email to recruit participants was circulated in the student email list in this university, with the website of the pilot system included; gifts of 4GB memory sticks were offered for those who would finish the pilot process. Potential volunteers were asked to visit the pilot system and to register into this system if they volunteered to participate. Finally, 13 students along with four graduate students from our lab participated and finished the pilot. These four graduate students acted as the volunteer leaders while the others acted as voluntary contributors in the pilot process. All participants were experienced social computing users. Since the system was "made" from scratch and there were no practical learning needs expressed by users at the beginning of the pilot, two co-construction tasks were provided to the four leaders for the purpose of the initial tryout, the topics of the tasks were "everyday healthcare tips" and "English of daily office conversation". The sample for the pilot does not represent the variety of participants expected to contribute learning resources, but does represent one key target contributor, higher education students.

Contributors were asked to take part in either of the two tasks after they read the descriptions that the leaders had published. Guided by the leaders, contributors took part in the activities of the tasks. The main stages of the tasks consisted of editing the script, creating or modifying materials according to the final script, and integrating materials into a resource package specified by the micro-learning resource information model. Templates for scripts and tools for material creating and packaging were provided in the system. At each stage, the edit permission for scripts, materials, and packages were subjected to change by the leaders. Contributors were encouraged to comment on different versions of the co-constructed products in which the leaders made the final decisions ( $\mathrm{Gu} \& \mathrm{Li}, 2010)$. The pilot process is outlined in Figure 3. After three weeks of co-construction in the system, all of the procedures in the pilot system were completed and the test was concluded. 


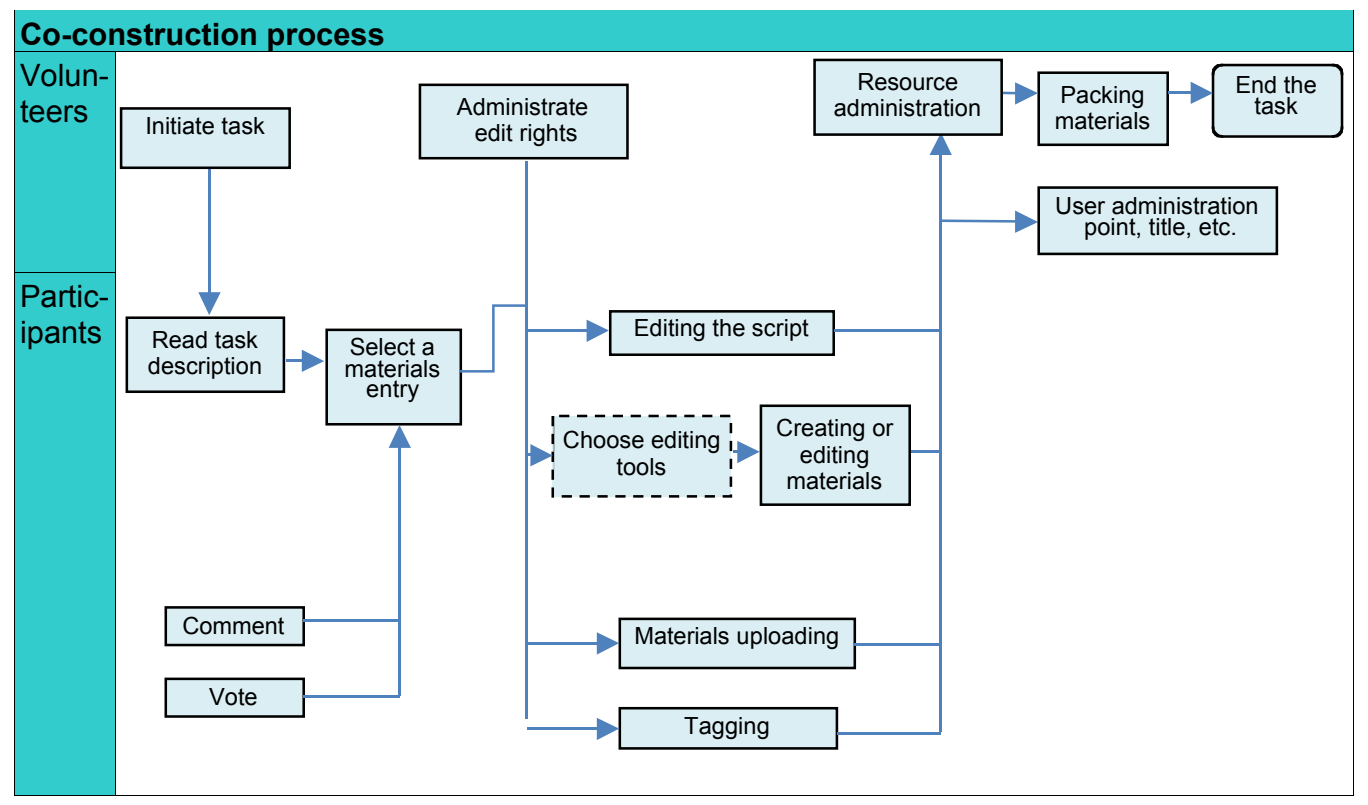

Figure 3: Pilot process

\section{Data collection}

Three types of data were collected in the pilot to see whether the intervention model, including its strategies, functions and tools, worked efficiently to facilitate this virtual community. Self-report question sheets were provided to the participants as they joined the system and started the co-construction activities. Twenty three questions were designed according to the intervention model, where 17 were designed using a 5-point Likert scale from 1 ('strongly disagree') to 5 ('strongly agree') while another six were designed as multiple-choice questions. Participants were asked to make self-reports as the collaboration activities moved on. Finished self-reports were collected at the end of the pilot. Meanwhile, system logs were also collected to indicate the level of participation in the pilot process.

In addition, a focus group meeting of participants was conducted at the end of the pilot, guided by a protocol with 18 questions, in an effort to find which functions, tools and strategies were most helpful and in which were in need of improvement. Participants were also asked to compare the features of the Co-Cons system with other social computing platforms they were familiar with. The focus group session was video recorded, and its transcript was coded and analysed using the intervention model to identify positive and negative points as well as gather suggestions for improving the intervention design.

All data collection was conducted in Chinese, from which the questionnaire data and quotations reporting in this article has been translated into English.

\section{Findings}

The results of the 17 questions using the 5-point scales on the self-report question sheets are described in Table 1. The fact that for most items the Median and the Mode are the 
same (except Q21 and Q22) and close to the highest point indicate that the participants hold similar and positive attitudes towards each item; meanwhile, the low interquartile range (IQR) also indicates little differences of attitudes between the participants.

Table 1: Results of self-report

\begin{tabular}{|c|c|c|c|c|c|}
\hline \multicolumn{3}{|r|}{ Question } & Md & M & IQR \\
\hline \multirow[t]{2}{*}{ Structural } & Q1 & Task describing is necessary & 5 & 5 & 1 \\
\hline & Q5 & Tools and activities help find people with same interests & 4 & 4 & 2 \\
\hline \multirow[t]{5}{*}{ Relational } & Q6 & The system meets personal needs according to my using habits & 3 & 3 & 0 \\
\hline & Q8 & Role list according to the sub-tasks is helpful & 4 & 4 & 1 \\
\hline & Q9 & Role description is a good idea to guide role and task selection & 5 & 5 & 1 \\
\hline & Q10 & First-come-first-choose help avoid conflict in role choosing & 5 & 5 & 2 \\
\hline & Q11 & Best practice and tutorials help understand what to do & 5 & 5 & 1 \\
\hline \multirow[t]{10}{*}{ Cognitive } & Q12 & Templates, tools and scripts are helpful in undertaking tasks & 5 & 5 & 1 \\
\hline & Q15 & $\begin{array}{l}\text { Guided procedure with templates and tools help to keep the } \\
\text { track of task }\end{array}$ & 5 & 5 & 1 \\
\hline & Q16 & Comments help improve products & 4 & 4 & 1 \\
\hline & Q17 & $\begin{array}{l}\text { Comments or votes of products help build trust in this } \\
\text { community }\end{array}$ & 4 & 4 & 1 \\
\hline & Q18 & Rubric helps to make comment & 4 & 4 & 0 \\
\hline & Q19 & Rubric makes me confident to make comments or votes & 4 & 4 & 1 \\
\hline & Q20 & The interface of the system attracts me & 4 & 4 & 1 \\
\hline & Q21 & The navigation is clear and I always know where I am & 4 & 5 & 1 \\
\hline & Q22 & The navigation is convenient & 4 & 5 & 2 \\
\hline & Q23 & The tools help and save my time in construction & 4 & 4 & 0.3 \\
\hline
\end{tabular}

Reliability: Cronbach alpha $=0.74 . \mathrm{Md}=$ Median; $\mathrm{M}=\mathrm{Mode} ; \mathrm{IQR}=$ Inter-quartile range

Coupled with the positive attitudes shown in the self-reports, the system log indicates that the participants actively took part in the co-construction process in the pilot, resulting in a total of 105 pieces of resources co-constructed with 297 versions in the whole process. On average, each user contributed to the community more than 17 times in the three-week pilot.

In general the results so far confirm the approach taken to develop a Co-Cons system that would show participation and sharing, however, the answers to the other six multiple-choice questions from the self-report question sheets indicate that the participants held concerns about the intervention design and had suggestions for how it could better work in the future. Suggestions for improvement also came from the focus group session. The following sections report findings from the focus group sessions and include responses from the answers to the six multiple-choice questions for support and further clarification.

Positive points and suggestions were obtained for the design of Structural perspective. In the focus group meeting, when asked about visiting the Co-Cons system and what attracted them to participate in the co-construction task, all participants mentioned that the Wall, on which they could post their wishes and ideas, was the most salient tool attracting them at the very beginning. However, after they registered in to the system and were ready to join the sharing tasks, the theme of the task (task description) and the amount of participants were the most important attracting factor, especially if they found their friends were participating. These points about being attracted to the system were also supported by responses to the question from selfreport, where most of them $(65 \%)$ indicated the choice of interest as the first attracting 
factor. Circulated messages with task information pushed them and the popularity of the top ten active contributors also helped attract users to join. The Wall and clearly described lists of tasks were also positive for Maintaining organisation, since they helped users to decide if they could join the tasks according to their interests, time and expertise. Yet, pushing a task's information through the Message box was thought to be unrealistic in a full scale implementation of the system with large numbers of users. Instead, task information should be pushed on a subscription basis to those who would be interested in particular themes. This idea was also supported in the selfreport questionnaire, where most of the participants $(59 \%)$ thought that the task information should only be pushed to those who would need it.

Other suggestions were made in the focus group sessions when the users were asked to compare this system with other social computing systems. Some users suggested the addition of features that are more entertaining or that meet the needs of the users to learn what their friends are doing as in news feed. These could be considered a strategy for attracting increased participation. Similarly, "attractive activity in the system" had the highest selection rate (53\%) in the self-report questions. Another suggestion was to release topics which fit users' interests and immediate objectives, thereby maintaining the virtual organisation's relevancy. Lastly, a detailed awards schema was also suggested as an important attractive feature to be included for the future operation of the system by more than half of the participants both from focus group and self-report data.

For the design towards Relational social capital, both positive and negative points were obtained from participants.

Similarly to the results of the self-report questions, role lists and role assignments were reported in focus group as being helpful for users to better understand different roles and related duties, and therefore to help users assume different roles according to their interests, time and expertise, when this topic was initiated by 'Let's talk about your experience of roles'. Finished resources co-constructed by people from the same community especially stimulated motivation and helped to build trust and confidence in the construction process; meanwhile, "best practice" was reported helpful for all of them to keep on editing and modifying so as to make the product under construction really perfect. Further, "best practice" also helped them to know how to edit good resources. Similar to "best practice" which could be viewed as a kind of borrowed experience, "previous experience and build more experience" was the highest selected item on the multiple-choice question asking them to reflect on trust and expectation in the task process. Further, accumulated points, credits and the resulting ranking list stimulated the users to join in and take part in different stages of tasks, although some of the users mentioned that they cared about the point/credit only because it determined their rights/permission to gain access to the system. This was confirmed by the answer to the multiple-choice question about accumulating credit, to which awards and sufficient resource/tools for the construction task shared the same selection rates when asking what factors made them more focused on the tasks.

The finished resource was unable to be displayed immediately until it was approved. This was reported in the focus group as a negative aspect to the strategy of "making results perceptible". Additionally, some of the participants complained that the whole process was not as simple as they expected. Also, one of the users felt stressed if she was listed in the ranking list. When asked to compare these features with other social 
computing platforms, a subject resource centre (an instance of social computing application) was mentioned, where only people with certain credit/points could download resources which could only be earned by contributing and sharing.

Concerning the design of the Cognitive perspective, positive and negative comments as well as suggestions of improvement were made in the focus group. Echoing the results from self-report questions, templates were found helpful in guiding the whole construct process, helping users to keep track of each stage and even making some stages considerably easier to handle. Meanwhile, comments from other community members stimulated users to contribute even more in the construction process. "I care about the comments from others whenever I upload a resource or something else. It keeps me back and sharing more". Here, mutually accepted comments also acted as an organisational maintenance factor, and all of the participants hoped that the resource which s/he helped to construct would be recommended as the 'recommended resource' in the homepage, therefore obtain "a sense of accomplishment", "a feeling of satisfaction", and "draw others' attention".

There were some negative aspects reported in the focus group towards our design for the Cognitive perspective. First, some frustration was expressed about task construction, since most of the tasks were not simple. Contributors said that although they were able to keep track of all the steps of a task, it took a lot of time and energy to persevere to completion of the task. Second, it was suggested that the system should provide more feedback for users. The users were interested in who actually commented on their resources, who edited or modified, or even just took a look at the resources that they helped to construct. Third, some contributors felt that more thought needed to be included in the marketing of the product so as to attract the activity of users. This point was supported by being the most selected answer for "attractive activity in the system" on the self-report questions. In the focus group participants further suggested that the Co-Cons designers should learn lessons from "QQ Farm" (a well-known virtual community in China) in which attractive activities such as "stealing" others' "plants," or monitoring the progress of seeds you have planted, tend to keep people working in the "community." Last, other suggestions such as displaying the download rate for the resources that you helped to construct was also mentioned in focus group. This was thought to be beneficial for generating sustainable interest in the community.

Moreover, focus group participants recommended improving the usability design of the homepage by comparing it unfavourably to homepages for more widely known social computing systems. In the focus group meeting, some users suggested removing part of the content displayed in the homepage, to leave only the most salient parts such as the 'recommended resource' and 'new update'. They felt the process of making comments should also be made easier since it is an essential element to the coconstruction process.

Finally, positive feedback was received regarding the role of the leader group. Contributors appreciated the active roles of this group of users who initiated, led, and facilitated the whole process. As well, contributors also like the idea that any one had the possibility of joining this elite group called the "Leader Group," and moreover the potential of earning the highest title in this system "Leader Member" stimulated increased contribution for some of our users. Thus, the opportunity to earn an upgrade to this level was a motivating factor for some participants. 


\section{Discussion}

The Co-Cons project implemented and tested a hypothetical model of social capital designed to attract participation and willingness to share in a social computing system. The results of our pilot implementation of Co-Cons provide new knowledge about how to stimulate participation and sharing in a complex co-construction process by means of policies and software functions and tools. The results also suggest a number of areas for systems improvement to best support users in co-construction. These results should be helpful in both the field of social computing research and for our future system development.

The findings in this first round pilot have helped us to better understand how to foster sharing and co-construction within online communities. First, the findings support our belief that the intervention model deliberately designed within the Co-Cons system fosters users to participate and maintain their activity in the community; and that, clearly outlined task descriptions help to bring together people who have mutual interests. These conclusions support Preece's ideas for how to establish purposeful community ties, especially when the call to participate is broadly sent to whomever would be interested. Further, the findings of users' high interests in the Wall and users' verbal appeal to incorporate more attractive activities confirm that a plan for maintaining interest stage by stage (Andrews et al. 2002; Andrews 2002) must be in place to maintain organisation. In addition, our findings indicate that knowing more about each other facilitates the participation; this could inspire further study on how to make use of friends of friends to harness social capital (Jackson \& Rogers, 2007).

Next, in agreement with prior studies (Wasko \& Faraj, 2005; Bock et al., 2005; Chen et al., 2009), we can conclude that taking advantage of participants' past experience helps to build identity, trust and expectation. Having members assume a role that is appropriate to their interest, time and expertise is beneficial. Similarly providing models such as "best practices" seems to be an effective way to guide successful performance. Also we learned that a more sophisticated awards schema is needed to better develop users' sense of obligation beyond what can be done with the current Accumulating credit strategy.

Finally, the results of our project show that the Co-Cons system supports participants coming together to develop learning products through a collaborative and mutually accepting process. The comments and reports from the participants show that they accepted the Co-Cons system as an online place for joint enterprise. Additionally we learned that structures, and functions keeping track, providing proper templates, tools and scripts can make the joint tasks easier to accomplish, by guiding the collective process, supporting the negotiation and creating mutual accountability (Wenger, 1998: $77,78)$. We also learned that the Co-Cons system needs improvement to become simple enough for users to easily contribute without investing too much time or effort; to find additional ways to make participating in Co-Cons attractive, and to improve the usability of the current design.

In conclusion, the results of our study provide general support for concluding that our design is effective. In a general way this provides support for our intervention model based on an objective of improving social capital. As an attempt to instantiate our intervention model to foster social capital and support participation and sharing, we see that the design works to facilitate a co-construction process in the pilot study: the 
strategies designed to attract participation and maintain organisation help build ties and organisation therefore helping to build structural social capital; strategies designed to orient to a role, make results perceptible and accumulate credit help build relational social capital; and strategies designed to keep participants on track, accepting of mutual outcomes and having appropriate tools help to build cognitive social capital. This study goes beyond explaining social capital by facilitating factors to cultivate and increase it.

However, there are limitations in this study. First, the short time period for the treatment in the pilot has limited external validity for how social capital may develop in natural practice. So we must be cautious in interpreting how and how much the designed intervention model helps to increase social capital. In addition, the participants who took part in the pilot have similar backgrounds, this is partly seen in similar attitudes from the self-reports we collected. The implications of these similarities are hard to judge but do limit generalisation to the eventual Co-Cons system which is expected to have diverse membership. These limitations need to be addressed in future iterations of our design research process, Our next steps are to carry out the modifications and improvements to the intervention design based on the findings of this pilot study. The next step in system testing will be carried out by encouraging participants from varied backgrounds and with different expertise which will be representative of the eventual lifelong learning network. Further our project will continue to advance our understanding of social capital in social computing and use that knowledge to improve how we assess social capital, as a by product of a well facilitated sharing community.

\section{Acknowledgment}

Source of funding: Research on mobile learning resource construction in the lifelong learning context, National Social Science Foundation (China), No. BCA080038.

\section{References}

Acar, A. (2008). Antecedents and consequences of online social networking behavior: The case of Facebook. Journal of Website Promotion, 3(1/2), 62-83.

Amiel, T. \& Reeves, T. C. (2008). Design-based research and educational technology: Rethinking technology and the research agenda. Educational Technology E Society, 11(4), 29-40. http:/ / ifets.info/journals/11_4/3.pdf

Andrews, D. C. (2002). Audience-specific online community design. Communications of the ACM, 45(4), 64-68.

Andrews, D., Preece, J. \& Turoff, M. (2002). A conceptual framework for demographic groups resistant to on-line community interaction. International Journal of Electronic Commerce, 6(3), 924.

Ardichvili, A. (2008). Learning and knowledge sharing in virtual communities of practice: Motivators, barriers, and enablers. Advances in Developing Human Resources, 10(4), 541-554.

Bock, G., Zmud, R. W., Kim, Y. \& Lee, J. (2005). Behavioral intention formation in knowledge sharing: Examining the roles of extrinsic motivators, social-psychological forces, and organizational climate. MIS Quarterly, 29(1), 87-111.

Brown, J. S. \& Duguid, P. (2001) Knowledge and organization: A social-practice perspective. Organization Science, 12(2), 198-213. 
Bruns, A. (2007). Produsage, Generation C, and their effects on the democratic process. In Media in Transition, 5, 27-29 April 2007, MIT, Boston. [verified 31 Mar 2011] http: / / eprints.qut.edu.au/7521/1/7521.pdf

Chen, I. Y. L., Chen, N.-S. \& Kinshuk (2009). Examining the factors influencing participants' knowledge sharing behavior in virtual learning communities. Educational Technology $\mathcal{E}$ Society, 12(1), 134-148. http:/ / www.ifets.info/journals/12_1/11.pdf

Chiu, C., Hsu, M. \& Wang, E. T. (2006). Understanding knowledge sharing in virtual communities: An integration of social capital and social cognitive theories. Decision Support Systems, 42(3), 1872-1888.

Coleman, J. S. (1990). The foundations of social theory. Harvard University Press, Cambridge, MA.

Daniel, B., McCalla, G. \& Schwier, R. (2002). A process model for building social capital in virtual learning communities. In Proceedings of the International Conference on Computers in Education, pp. 574-575. IEEE Computer Society.

Ganley, D. \& Lampe, C. (2009). The ties that bind: Social network principles in online communities. Decision Support Systems, 47(3), 266-274.

Ginsburg, M. \& Weisband, S. (2002). Social capital and volunteerism in virtual communities: The case of the Internet Chess Club. In Proceedings of the 35th Annual Hawaii International Conference on System Sciences (HICSS'02) - Volume 7 (p. 171.2). IEEE Computer Society.

Goggins, S. P., Laffey, J. \& Tsai, I. (2007). Cooperation and groupness: Community formation in small online collaborative groups. In Proceedings of the 2007 International ACM Conference on Supporting Group Work (pp. 207-216). Sanibel Island, Florida, USA: ACM.

$\mathrm{Gu}$, X. \& Li, S. (2010). Co-Construct micro learning resource: System design and implementation mechanism. China Educational Technology, 2, 74-79 (in Chinese).

Gu, X. \& Zha, C. (2008). Mechanism design and its enabling tools in a collaborative research technology system. E-learning Research, 8, 9-18 (in Chinese).

Hendriks, P. (1999). Why share knowledge? The influence of ICT on the motivation for knowledge sharing. Knowledge and Process Management, 6(2), 91-100.

Hsu, M., Ju, T. L., Yen, C. \& Chang, C. (2007). Knowledge sharing behavior in virtual communities: The relationship between trust, self-efficacy, and outcome expectations. International Journal of Human-Computer Studies, 65(2), 153-169.

Jiang, H. \& Carroll, J. M. (2009). Social capital, social network and identity bonds: A reconceptualization. Proceedings of the Fourth International Conference on Communities and Technologies (pp. 51-60). University Park, PA, USA: ACM.

Jackson, M. O. \& Rogers, B. W. (2007). Meeting strangers and friends of friends: How random are social networks? The American Economic Review, 97(3), 890-915.

Kalmus, V., Pruulmann-Vengerfeldt, P., Runnel, P. \& Siibak, A. (2009). Mapping the terrain of "Generation C": Places and practices of online content creation among Estonian teenagers. Journal of Computer-Mediated Communication, 14(4), 1257-1282. [verified 31 Mar 2011] http: / / onlinelibrary.wiley.com/ doi/10.1111/j.1083-6101.2009.01489.x/ full

Lave, J. \& Wenger, E. (1991). Situated learning: Legitimate peripheral participation. Cambridge University Press.

Lin, M. J., Hung, S. \& Chen, C. (2009). Fostering the determinants of knowledge sharing in professional virtual communities. Computers in Human Behavior, 25(4), 929-939. 
Nahapiet, J. \& Ghoshal, S. (1998). Social capital, intellectual capital, and the organizational advantage. The Academy of Management Review, 23(2), 242-266.

Nielsen, J. (2006). Participation inequality: Encouraging more users to contribute. [viewed 20 Feb 2011] http: / / www.useit.com/alertbox/participation_inequality.html

Parameswaran, M. \& Whinston, A. B. (2007). Research issues in social computing. Journal of the Association for Information Systems, 8(6), 336-350. http:/ / aisel.aisnet.org/ jais/vol8 / iss6/22 /

Preece, J. (2000). Online communities: Designing usability, supporting sociability. Chichester, UK: John Wiley \& Sons.

Raban, D. R. \& Rafaeli, S. (2007). Investigating ownership and the willingness to share information online. Computers in Human Behavior, 23(5), 2367-2382.

Smith, M. S. (2008). Social capital in online communities. In Proceedings of the 2 nd PhD Workshop on Information and Knowledge Management (pp. 17-24). Napa Valley, California, USA: ACM.

Tsai, W. (2002). Social structure of "coopetition" within a multiunit organization: Coordination and intrarganizational knowledge sharing. Organization Science, 13(2), 179-190. [verified 3 Apr 2011] http: / / www.personal.psu.edu / faculty / w / p/ wpt1/Social $\% 20$ Structure $\% 20 \mathrm{of} \% 20$ Coopetition $\%$ 20Within $\% 20$ a\% 20Multiunit\%20Organization $\% 20$ Coordination, \%20Competitio n, \%20and $\% 20$ Intraorganizational $\% 20$ Knowledge $\% 20$ Sharing.pdf

Wang, F. Y. (2007). Toward a paradigm shift in social computing: The ACP approach. Intelligent Systems, 22(5), 65-67. http:/ / www.computer.org/portal/web/csdl/doi/10.1109/MIS.2007.98

Wasko, M. \& Faraj, S. (2005). Why should I share? Examining social capital and knowledge contribution in electronic networks of practice. MIS Quarterly, 29(1), 35-57.

Wenger, E. (1998). Communities of practice: Learning, meaning and identity. Cambridge, UK: Cambridge University Press.

Yang, S. \& Farn, C. (2009). Social capital, behavioral control, and tacit knowledge sharing: A multi-informant design. International Journal of Information Management, 29(3), 210-218.

Authors: Xiaoqing Gu (author for correspondence)

Department of Educational Information Technology, East China Normal University 3663 Zhongshan Road North, Shanghai, China 200062

Email:xqgu@ses.ecnu.edu.cn, guxq@hotmail.com

Chongping Zha, Department of Physics and Electronic Engineering, Qujing Normal University, China

Shusu Li, Department of Educational Information Technology, East China Normal University, China

James M. Laffey, School of Information Science and Learning Technologies, University of Missouri-Columbia, USA

Please cite as: Gu, X., Zha, C., Li, S. \& Laffey, J. M. (2011). Design, sharing and coconstruction of learning resources: A case of lifelong learning communities in Shanghai. Australasian Journal of Educational Technology, 27(2), 204-220.

http: / / www.ascilite.org.au/ajet/ajet27/gu.html 